\title{
An overview of AVF maturation and endothelial dysfunction in an advanced renal failure
}

\author{
Muhammad A. Siddiqui ${ }^{1,3^{*}}$ (D), Suhel Ashraff ${ }^{2}$, Derek Santos ${ }^{1}$ and Thomas Carline ${ }^{1}$
}

\begin{abstract}
Life expectancy in patient with established kidney failure is considerably shortened with worsening quality of life. Through the provision of renal replacement therapy, survival and quality of life of advanced renal disease patients can be markedly improved. Haemodialysis and peritoneal dialysis are the treatment modalities in patients with end-stage renal disease. The efficiency of haemodialysis treatment relies on the functional status of vascular access. Vascular access and its related problems represent the main factors that determine a rise in the rate of incidence of the disease among haemodialysis patients and, consequently, a rise in the healthcare expenses. Arteriovenous fistula is the most efficient method, as it has a low risk of infection and mortality, and can ensure long-term functional access. However, maturation of an arteriovenous fistula is a complex process and is not well understood; significant numbers of arteriovenous fistula fail to develop sufficiently prior to their use for haemodialysis due to either lack of vessel maturation or spontaneous thrombosis. There are multiple blood markers and human factors that contribute to the maturation of fistula. Endothelial function is one of the most important determinants of arteriovenous fistula maturation. Early fistula failure is usually due to thrombosis which can be triggered by haematoma, by low flow rates resulting from low blood pressure, or by a hypercoagulable state. Impairment of endothelial function is associated with decreased arterial remodelling and final venous lumen diameter. Arteriovenous fistula anastomoses need early proliferation of endothelial cells to restore the barrier, permeability, and biochemical monitoring roles of endothelial cells in managing vascular repair, local thrombosis, neointimal hyperplasia, and inflammation. The purpose of this review was to discuss the maturation of AVF and endothelial dysfunction.
\end{abstract}

Keywords: End-stage kidney disease, Renal replacement therapy, Haemodialysis, Arteriovenous fistula, Endothelial dysfunction

\section{Background}

Chronic kidney disease (CKD) is a critical condition with considerable public health implications. The global mean (95\% CI) CKD prevalence in five stages was $13.4 \%$ (11.715.1\%) and stages $3-5$ was $10.6 \%(9.2-12.2 \%)$ [1]. In 2014, the number of adult patients starting renal replacement therapy (RRT) in the UK was 7411 equating to an incidence rate of 115 pmp, compared with 109 pmp in 2013 [2]. There are a number of factors, which have to be taken into account when deciding the usage of RRT in patients suffering from advanced renal disease, such as evaluation of electrolyte and acid-base balance, intravascular volume, uraemia,

\footnotetext{
* Correspondence: drasadi@hotmail.com

'School of Health Sciences, Queen Margaret University, Edinburgh, UK

${ }^{3}$ Professional Faculties, University of Calgary, Calgary, Canada

Full list of author information is available at the end of the article
}

dietary needs, haemodynamic status, urine output, and the pathology of the disease in each individual case. The benefits of RRT have to be compared with the possible hazards of surgical intervention, such as bleeding caused by anticoagulants, as well as all types of complications that accompany the central venous access. Many patients with chronic kidney disease are still unknown, because the serum creatinine fails to identify decreasing kidney function, especially in women and old individuals $[3,4]$. According to the Quality and Outcomes Framework, the diagnosis of chronic kidney disease and improvement of treatments will be mediated by the introduction of estimated glomerular filtration rate (eGFR) reporting, as well as by the preservation of patient records required of all the UK general practitioners [5].

Dialysis and transplantation provide alternative ways of taking over the work of advanced renal disease patients. The most efficient form of therapy for advanced 
renal disease patients is a kidney transplant. However, haemodialysis is the next best option. The efficiency of haemodialysis treatment relies on a functional status of vascular access (VA). According to the National Institute for Health and Clinical Excellence Guidelines [6], VA and its related problems represent the main factors that determine a rise in the rate of incidence of the disease among haemodialysis patients and, consequently, a rise in the healthcare expenses. To ensure that the dialysis therapy can be efficiently undertaken, all patients need a fully developed fistula that is appropriate for the process of cannulation. Arteriovenous fistula (AVF) is the most efficient method, as it has a low risk of infection and mortality, and can ensure long-term functional access $[7,8]$. Unfortunately, significant numbers of AVF fail to develop sufficiently prior to their use for haemodialysis due to either lack of vessel maturation or spontaneous thrombosis [9].

It is likely that one of the most important determinants of AVF maturation is the ability of the inflow artery and the outflow vein to respond to the increased blood flow that occurs upon anastomosis of the artery and vein [10]. AVF maturation is the ability of the inflow artery and the outflow vein to respond to the increased blood flow that occurs upon anastomosis of the artery and vein. A healthy response to the anastomosis is an increase in blood flow and corresponding increase in shear stress [11] which stimulates the endothelial cells to release nitric oxide (NO) and other vasodilatory substances [12]. The main purpose of this review was to discuss the maturation of AVF and endothelial dysfunction in an advance kidney disease.

\section{Haemodialysis}

Progressive and permanent renal failure is most frequently treated with haemodialysis. RRT with haemodialysis does not provide true replacement of renal function. However, by removing waste solutes and excess body water and restoring biochemical and acid-base balance, haemodialysis has considerably improved the morbidity and mortality of end-stage renal disease (ESRD) patients. A suitable type of vascular access has to be created to establish a connection between the circulation system of the patient and the haemodialysis cycle, in order to provide haemodialysis in ESRD patients.

Vascular access problems represent the main determinant of morbidity among haemodialysis patients and put a considerable degree of financial pressure on the healthcare sector $[13,14]$. Successful haemodialysis depends on the provision of safe, efficient, and durable vascular access. Establishing and maintaining effective vascular access is a demanding process for both patients and renal services. These demands are set to increase in response to an RRT population that is becoming increasingly dependent on haemodialysis, whilst also increasing in population size, age, and co-morbidity. Vascular access can be divided into three categories: arteriovenous fistula, central venous catheter (CVC) and arteriovenous graft (AVG).

Of these, CVCs are used temporarily to provide vascular access for haemodialysis whilst the patient awaits creation or maturation of an AVF or AVG or because no suitable options for permanent vascular access are available [15]. AVF is considered to provide the best longterm functional vascular access, with a reduced risk of thrombosis or infection, and is the most cost-effective [16]. There are logistical hurdles to this late presentation to renal services, fitness for surgery, suitable peripheral vascular anatomy, delays due to primary or secondary access failure, and slow rates of AVF maturation.

Konner et al. [17] had also obtained a high success rate (70-90\%) of native AVF construction in their study on a randomized sample of ESRD patients. Despite the fact that it is not without its problems, the arteriovenous fistula offers better quality access for dialysis as it has a long-lasting primary patency rate, avoids the need for other numerous procedures, and has the most reduced rates of morbidity and mortality among all types of vascular access [18].

\section{Endothelial function}

The endothelium is the largest organ in the body consisting of endothelial cells lining every blood vessel. Adults possess enough endothelial cells that cover a surface area of approximately 1 to $7 \mathrm{~m}^{2}$, with a total weight of around $1 \mathrm{~kg}$ and a total quantity of 1013-6078 individual cells [19]. In healthy subjects, vascular endothelium has many functions: it can identify hormonal stimuli (vasoactive substances) as well as mechanical stimuli (pressure and shear stress). Endothelial cells regulate inflammation, cell proliferation, coagulation, and vascular tone due to their output of a number of compounded substances [20]. Endothelium produced vasodilatory materials such as C-type natriuretic peptide, various endothelium-derived hyperpolarising elements, prostacyclin, and NO, whereas vasoconstrictor materials are reactive oxygen species, thromboxane $\mathrm{A} 2$, angiotensin II, and endothelin-1 [21]. In addition, there are a number of inflammatory regulators, such as nuclear factor-kB, vascular cell adhesion molecule-1, E-selectin, $\mathrm{NO}$, and intercellular adhesion molecule-1 which play an integral part of endothelial function.

Gresele et al. reported that fibrinogen, prostacyclin, thromboxane A2, plasminogen activator inhibitor-1, NO, tissue factor inhibitor, von Willebrand factor, and plasminogen activator act as modulators for haemostasis [22]. Permeability, inflammation, coagulation, cell adhesiveness, and vascular tone are among the variety of 
local blood vessel operations modulated by endothelium. In medium to large arteries, healthy endothelial cells contribute to the prevention of atherosclerosis by inhibiting platelet activation, limiting the entry of cells and lipids into the vessel wall, and maintaining a nonproliferative and biochemically inactive intima [23].

\section{Endothelial dysfunction}

Endothelial dysfunction occurs when there is an imbalance between the vasoconstricting and vasodilating products (produced directly or indirectly by the endothelium) [24]. Endothelial cell dysfunction can be caused by multiple factors such as genetics, advance glycation end products, hyperglycaemia, high blood cholesterol, hypertension, obesity, diabetes, and smoking [25]. It is associated with higher aggregation of platelets and anticoagulant properties; decreased production of NO; higher secretion of cytokines, chemokines, or adhesion molecules; and increased reactive oxygen species production from the endothelium [26]. Furthermore, individuals suffering from chronic kidney failure exhibit endothelial cell dysfunction. There is also a link between metabolic changes to nitric oxide synthase (NOS) and chronic kidney disease $[27,28]$. NOS is available to endothelial cells in two types of isoform: inducible and constitutive or iNOS and cNOS, respectively [29]. Physiological vascular dilation is significantly affected by the constitutive isoform. In patients with advanced renal disease, decreased NO production from cNOS has been observed as a mechanism leading to impaired endothelium-dependent vasodilation in uraemia [30]. Furthermore, Passauer et al.'s research found a correlation between reduced NO production and reduced endothelium-based vasodilation in dialysis patients [31]. The major features of endothelial dysfunction are recapped in Table 1.

Endothelial dysfunction is also associated with increased oxidative stress and inflammatory changes that play a role in the development and progression of atherosclerosis in the early stages, while they increase the vulnerability of fully developed plaques facilitating their rupture [32]. There are many techniques used to assess endothelial function. These techniques can be either invasive or non-invasive. In invasive techniques, vasoactive agents are delivered via intra-arterial infusion, whilst the response is measured with high-resolution ultrasound or strain gauge plethysmography. In addition, intravascular infusions of vasoactive stimulants can be combined with intravascular ultrasound.

Non-invasive techniques includes ultrasound and magnetic resonance imaging flow-mediated dilatation, salbutamol-mediated endothelial function measured by pulse wave analysis or pulse contour analysis, and peripheral arterial tonometry [33, 34]. Ultrasound flowmediated dilatation of the brachial artery is the most widely used in clinical research, and it is currently considered a standard for a non-invasive assessment of conduit artery endothelial function [35].

\section{Endothelium dysfunction and AVF maturation}

Early fistula failure is usually due to thrombosis which can be triggered by haematoma, by low flow rates resulting from low blood pressure, or by a hypercoagulable state [36]. On the other hand, progressive neointimal hyperplasia in the venous outflow system can lead to stenosis, which can cause late thrombosis of haemodialysis AVF [37, 38]. Arteriovenous fistula anastomoses need swift proliferation of endothelial cells to restore the barrier, permeability, and biochemical monitoring roles of endothelial cells in managing vascular repair, local thrombosis, neointimal hyperplasia, and inflammation [39]. Because the migration and proliferation of endothelial cells are restricted by uraemia, and because uraemia causes abnormal vascular remodelling, neointimal hyperplasia can sometimes be found at the point of anastomosis of VA [40, 41]. This results in primary access failure and ineffective dialysis [42]. A recent study suggested that microvascular endothelial function as measured using peripheral arterial tonometry may be useful as a predictor of AVF maturation and function [10]. Patients who had impaired flow-mediated dilation (FMD) with a median value of $5.0 \%$ (3-9) did not find any difference between the patients with successful and/or unsuccessful AVF [10]. The finding of impaired endothelial

Table 1 Healthy and dysfunctional endothelium

\begin{tabular}{|c|c|}
\hline Healthy endothelium & Endothelial dysfunction \\
\hline Vasodilatory $\left(\uparrow N O, \uparrow P G I_{2}\right)$ & Impaired vasodilation $\left(\downarrow N O, \downarrow P G I_{2}\right)$ \\
\hline Decrease oxidative stress, $\downarrow$ uric acid & Increase oxidative stress ( $\uparrow$ nitrotyrosine and uric acid) \\
\hline Anticoagulant ( $\downarrow P A I-1, v W F$, P-selectin) & Procoagulant ( $\uparrow$ PAl-1, VWF, P-selectin) \\
\hline $\begin{array}{l}\text { Rise in endothelial progenitor cells and decrease molecular markers } \\
\text { of damage (circulating endothelial cells, microparticles) }\end{array}$ & $\begin{array}{l}\text { Decrement in endothelial progenitor cells and increase molecular markers } \\
\text { of damage (circulating endothelial cells, microparticles) }\end{array}$ \\
\hline $\begin{array}{l}\text { Anti-inflammatory biomarkers ( } \downarrow \text { sICAM, sVCAM, E-selectin, CRP, } \\
\text { TNF-alpha, IL-6, MCP-1) }\end{array}$ & $\begin{array}{l}\text { Pro-inflammatory biomarkers ( } \uparrow \text { sICAM, sVCAM, E-selectin, CRP, TNF-alpha, } \\
\text { IL-6, MCP-1) }\end{array}$ \\
\hline
\end{tabular}

CRP C-reactive protein, IL-6 interleukin-6, NO nitric oxide, PAI-1 plasminogen activator inhibitor 1, PGI2 prostacyclin, s/CAM soluble intercellular adhesion molecule, sVCAM soluble vascular cell adhesion molecule, TNF- $a$ tumour necrosis factor alpha, vWF von Willebrand factor 
function in this CKD cohort is similar to what others have shown using both venous occlusion plethysmography techniques [43], and FMD [44]. Owens et al. [45] determined FMD among 25 CKD patients prior to AVF creation and found very similar values $(5.8 \pm 1.0 \%)$. Study explored the correlation between baseline FMD and subsequent change in the diameter of the artery and vein at 3 months after AVF creation and found a positive correlation.

Erdem et al. discovered that during haemodialysis, turbulent flow, intraluminal pressure, and regular needle insertion caused endothelial damage, which led to haemostatic activation in AVF [46]. Wakefield et al.'s study indicated that thrombus development and blood clotting could be stimulated by higher levels of factor V, plasminogen activator inhibitor-1, tissue factor, and von Willebrand factor, as secreted by a dysfunctional venous endothelium [47]. Furthermore, a dysfunctional venous endothelium favours the interactions with circulating tissue factor-bearing microparticles, further triggering localized blood clotting activation [48].

Vascular stenosis of arteriovenous fistula is primarily the result of neointimal hyperplasia $[49,50]$. The pathophysiology of neointimal hyperplasia consists of the presence of extracellular matrix deposition and proliferation, adherence, and migration of vascular smooth muscle cell (VSMC), which represents abnormal healing. Sung et al. [51] found that growth factors and cytokines act as semi-regulators for the changes to the VSMC response. Tumour necrosis factor- $\alpha$ stimulates the synthesis of other pro-inflammatory cytokines and adhesion molecules; it has a chemotactic activity for monocytes and stimulates migration and proliferation of VSMC.
The shear stress levels revert back to baseline due to these vascular reactions (Fig. 1). On the other hand, the activation of endothelial cells and proliferation, release of inflammatory and procoagulant substances, and alterations to cellular shape are all events that have been linked to reduction in shear stress and blood flow. This manifests as raised levels of neointimal hyperplasia and vascular constriction [52]. Furthermore, Dardik et al. [53] has revealed that vascular response seems to be significantly influenced by the exact type of shear stress. For instance, matrix metalloproteinase up-regulation, higher proliferation of cells, and a pro-inflammatory environment can be caused by oscillatory shear stress [54]. On the other hand, normal dilatation and endothelial stability are the outcomes of laminar shear stress [55].

Corpataux et al. [56] discovered that the fistula vein instantly deals with huge increase in blood flow following the creation of AVF. Additionally, there is an eventual thickening of the fistula vein wall and dilation of the venous lumen. This allows the fistula vein to effectively deliver sufficient blood for haemodialysis and be regularly needled for dialysis circulation. The next most significant hemodynamic factor that typically influence an AV fistula is the circumferential or transmural pressure. Transmural pressure is produced inside the blood vessel, and previous studies $[57,58]$ have shown that increase in transmural pressure lead to an activation of smooth muscle cells, higher levels of extracellular matrix elements, and raised production of cytokine. These pathways invariably lead to the thickening of blood vessel wall, which result in the reduction of transmural pressure which revert back to basal level.

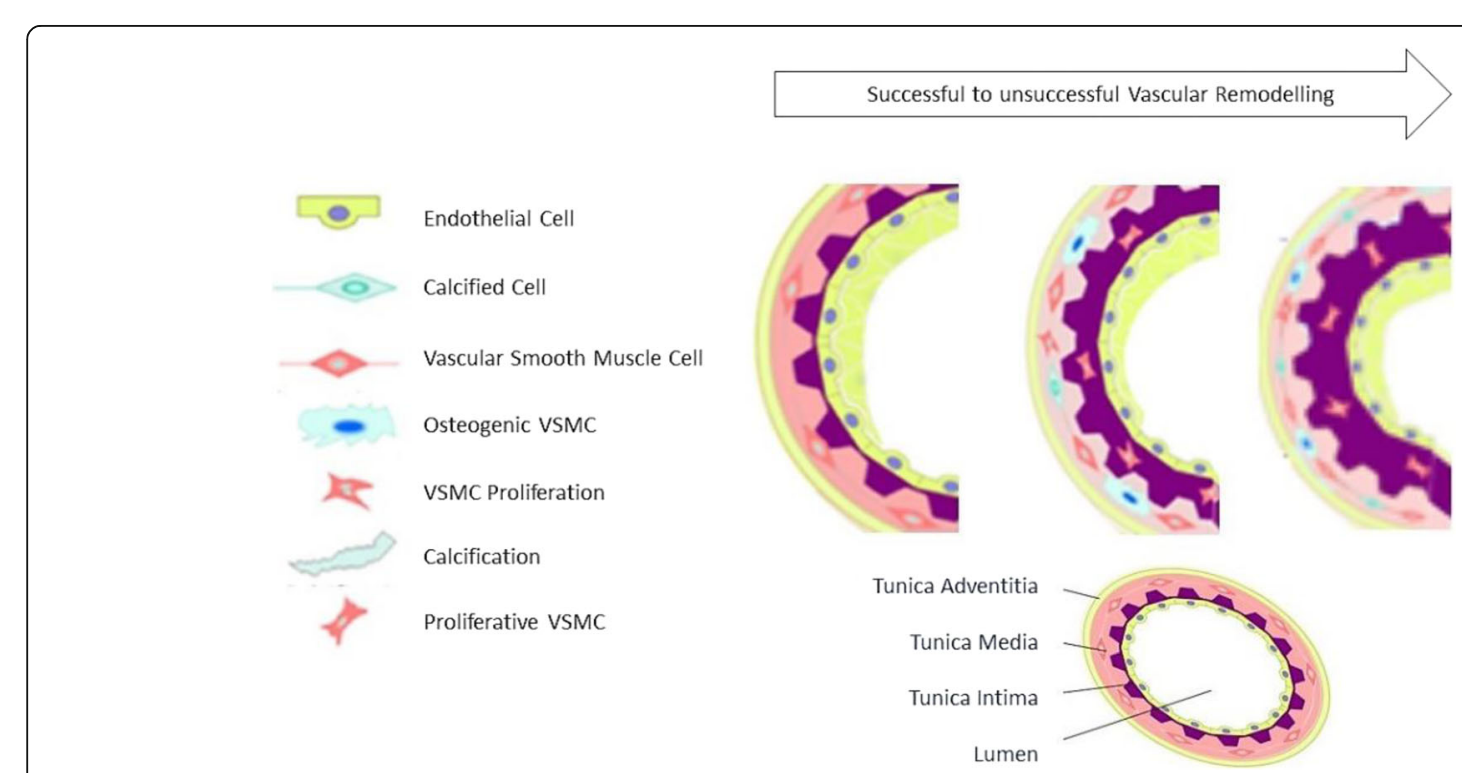

Fig. 1 Vascular remodelling responses 
Vanholder et al. [59] and Cardinal et al. [60] indicated that wound healing, migration, proliferation, viability, and other fundamental endothelial cells biological processes are restricted by the uraemic toxins found in the plasma of individuals with ESRD. This is particularly true at the site of haemodialysis vascular access. The failure of these EC processes has played a crucial role in vascular remodelling. According to Chitalia et al. [61], vascular remodelling is negatively impacted by EC dysfunction that is caused by uraemia. The result of this is vascular access failure and can be fatal to patients with ESRD since it is crucial to achieve vascular access for haemodialysis.

Certainly, endothelial cell function is also important, but the most important factor in maturation of AVF seems to be blood vessel selection and surgical technique. Blood vessel selection is one the most important factors in the maturation of AVF. The inadequate vessels used to construct AVFs have been identified as another cause of AVF failure. Zadeh et al. [62] conducted a cross-sectional study using a sample of 96 haemodialysis patients and found an association between the vein diameter and the success rate of fistula development. A vein diameter of $<2.5 \mathrm{~mm}$ is supposed to be considered inadequate for formation of an AVF, particularly if measurements remain unchanged following the use of tourniquet [63].

\section{Conclusion}

The efficiency of haemodialysis treatment relies on a functional status of vascular access. AVF non-maturation is most commonly characterized by a juxta-anastomotic stenosis, a histological level such as aggressive neointimal hyperplasia at the juxta-anastomosis, and an absence of outward vascular remodelling. Currently, we have reasonable understanding of the mechanisms, pathways, pathology, and the pathogenesis of venous neointimal hyperplasia, and vascular stenosis leads to AVF nonmaturation. The combination of advances in cellular and molecular pathobiology, biomaterials, and drug delivery techniques has resulted in many innovative therapies for neointimal hyperplasia. There is a need to identify the therapies that are best suited for clinical use in AVF dysfunction.

\footnotetext{
Abbreviations

AVF: Arteriovenous fistula; AVG: Arteriovenous graft; CKD: Chronic kidney disease; CVC: Central venous catheter; eGFR: Estimated glomerular filtration rate; ESRD: End-stage renal disease; FMD: Flow-mediated dilation; NO: Nitric oxide; NOS: Nitric oxide synthase; RRT: Renal replacement therapy; VA: Vascular access; VSMC: Vascular smooth muscle cell
}

\section{Acknowledgements}

Not applicable.

\section{Funding}

No funding was obtained.
Availability of data and materials

Not applicable.

\section{Authors' contributions}

MAS conceived the study and supervised the study. MAS and SA drafted the manuscript while DS and TC revised and reviewed the whole manuscript.

All authors read and approved the final manuscript.

Ethics approval and consent to participate

Not applicable as a literature review.

\section{Consent for publication}

Not applicable.

\section{Competing interests}

The authors declare that they have no competing interests.

\section{Publisher's Note}

Springer Nature remains neutral with regard to jurisdictional claims in published maps and institutional affiliations.

\section{Author details}

${ }^{1}$ School of Health Sciences, Queen Margaret University, Edinburgh, UK. ${ }^{2}$ Diabetes and Endocrinology, James Cook University Hospital, Middlesbrough, UK. ${ }^{3}$ Professional Faculties, University of Calgary, Calgary, Canada.

Received: 13 March 2017 Accepted: 25 July 2017

Published online: 02 October 2017

\section{References}

1. Hill NR, Fatoba ST, Oke JL, Hirst JA, O'Callaghan CA, Lasserson DS, et al. Global prevalence of chronic kidney disease-a systematic review and meta-analysis. PLoS One. 2016;11(7):e0158765.

2. Gilga J, Caskeyabc F, Fogarty D. UK Renal Registry 18th Annual Report: chapter 1 UK renal replacement therapy incidence in 2014: national and centre-specific analyses. Nephron. 2016;132(1):9-40.

3. Drey N, Roderick P, Mullee M, Rogerson M. A population-based study of the incidence and outcomes of diagnosed chronic kidney disease. Am J Kidney Dis. 2003:42:677-84.

4. John R, Webb M, Young A, Stevens PE. Unreferred chronic kidney disease: a longitudinal study. Am J Kidney Dis. 2004;43:825-35.

5. Quality and Outcomes Framework. 2015. [Online]. Available from: http://www.qof.ic.nhs.uk. [Accessed 22 Dec 2016].

6. National Institute for Health and Care Excellence (NICE). Chronic kidney disease in adults: assessment and management. Clinical guideline [CG182]. London; 2014.

7. Lyem H. Early follow-up results of arteriovenous fistulae created for haemodialysis. Vasc Health Risk Manag. 2011;7:321-5.

8. Dixon BS, Novak L, Fangman J. Haemodialysis vascular access survival: upper-arm native arteriovenous fistula. Am J Kidney Dis. 2002;39:92-101.

9. Asif A, Cherla G, Merrill D, Cipleu CD, Briones P, Pennell P. Conversion of tunnelled haemodialysis catheter con-signed patients to arteriovenous fistula. Kidney Int. 2005;67:2399-407.

10. MacRae JM, Ahmed S, Hemmelgarn B, Sun Y, Martin BJ, Roifman I, et al. Role of vascular function in predicting arteriovenous fistula outcomes: an observational pilot study. Can J Kidney Health Dis. 2015;2:19.

11. Robbin ML, Chamberlain NE, Lockhart ME, Gallichio MH, Young CJ, Deierhoi MH, et al. Hemodialysis arteriovenous fistula maturity: US evaluation. Radiology. 2002;225(1):59-64.

12. Budu-Grajdeanu P, Schugart RC, Friedman A, Valentine C, Agarwal AK, Rovin BH, A mathematical model of venous neointimal hyperplasia formation. Theor Biol Med Model. 2008:5:2-11.

13. USRDS (US Renal Data System). Annual data report: atlas of chronic kidney disease and end-stage renal disease in the United States. Bethesda: National Institutes of Health, National Institute of Diabetes and Digestive and Kidney Diseases; 2011.

14. MacNeill SJ, Casula A, Shaw C, Castledine C. UK Renal Registry 18th Annual Report: chapter 2 UK renal replacement therapy prevalence in 2014: national and centre-specific analyses. Nephron. 2016;132(1):41-68.

15. Bourquelot P. Vascular access for haemodialysis. Nephrol Ther. 2009;5(3):239-438. 
16. Manns B, Tonelli M, Yilmaz S, Lee H, Laupland K, Klarenbach S, et al. Establishment and maintenance of vascular access in incident haemodialysis patients: a prospective cost analysis. J Am Soc Nephrol. 2005;16:201-9.

17. Konner K, Nonnast DB, Ritz E. The arteriovenous fistula. J Am Soc Nephrol. 2003;14:1669-80

18. Anel RL, Yevzlin AS, Ivanovich P. Vascular access and patient outcomes in haemodialysis: questions answered in recent literature. Art if Organs. 2003;27:237.

19. Augustin $\mathrm{HG}$, Kozian DH, Johnson RC. Differentiation of endothelial cells: analysis of the constitutive and activated endothelial cell phenotypes. BioEssays. 1994;16(12):901-6.

20. Kolluru GK, Bir SC, Kevil CG. Endothelial dysfunction and diabetes: effects on angiogenesis, vascular remodelling, and wound healing. Int J Vasc Med. 2012:01-30.

21. Schiffrin EL. A critical review of the role of endothelial factors in the pathogenesis of hypertension. J CardiovasC Pharmacol. 2001;38(2):S3-6.

22. Gresele P, Momi S, Migliacci R. Endothelium, venous thromboembolism and ischaemic cardiovascular events. Thromb Haemost. 2010;103(1):56-61.

23. Antonov AS, Munn DH, Kolodgie FD, Virmani R, Gerrity RG. Aortic endothelial cells regulate proliferation of human monocytes in vitro via a mechanism synergistic with macrophage colony-stimulating factor. Convergence at the cyclin E/p27kip1 regulatory checkpoint. J Clin Invest. 1997;99(12):2867-76.

24. Deanfield J, Donald A, Ferri C, Giannattasio C, Halcox J, Halligan S, et al. Endothelial function and dysfunction. Part I: methodological issues for assessment in the different vascular beds: a statement by the Working Group on Endothelin and Endothelial Factors of the European Society of Hypertension. J Hypertens. 2005;23(1):7-17.

25. Goligorsky MS. Endothelial cell dysfunction: can't live with it, how to live without it. Am J Physiol Renal Physiol. 2005;288(5):871-80.

26. Al-lsa AN, Thalib L, Akanji AO. Circulating markers of inflammation and endothelial dysfunction in Arab adolescent subjects: reference ranges and associations with age, gender, body mass and insulin sensitivity. Atherosclerosis. 2010;208(2):543-9.

27. Dandona P, Chaudhuri A, Aljada A. Endothelial dysfunction and hypertension in diabetes mellitus. Med Clin North Am. 2004;88:911-31. x-xi

28. Yu Y, Lyons TJ. A lethal tetrad in diabetes: hyperglycemia, dyslipidemia, oxidative stress, and endothelial dysfunction. Am J Med Sci. 2005;330:227-32

29. Kharbanda RK, Deanfield JE. Functions of the healthy endothelium Coron Artery Dis. 2001;12(6):485-91.

30. Santoro D, Bellinghieri G, Conti G, Pazzano D, Satta E, Costantino G, et al. Endothelial dysfunction in chronic renal failure. J Ren Nutr. 2010;20(5 Suppl):S103-S8.

31. Passauer J, Pistrosch F, Büssemaker E, Lässig G, Herbrig K, Gross P. Reduced agonist-induced endothelium-dependent vasodilation in uremia is attributable to an impairment of vascular nitric oxide. J Am Soc Nephrol. 2005;16:959-65.

32. Verma S, Anderson TJ. Fundamentals of endothelial function for the clinical cardiologist. Circulation. 2002;105:546-9.

33. Al-Qaisi M, Kharbanda RK, Mittal TK, Donald AE. Measurement of endothelial function and its clinical utility for cardiovascular risk. Vasc Health Risk Manag. 2008:4(3):647-52

34. Hansell J, Henareh L, Agewall S, Norman M. Non-invasive assessment of endothelial function - relation between vasodilatory responses in skin microcirculation and brachial artery. Clin Physiol Funct Imaging. 2004:24(6):317-22.

35. Higashi Y. Assessment of endothelial function. History, methodological aspects, and clinical perspectives. Int Heart J. 2015;56(2):125-34. doi:10.1536/ihj.14-385.

36. Konner K. Primary vascular access in diabetic patients: an audit. Nephrol Dial Transplant. 2000;15(9):1317-25.

37. De Marchi S, Falleti E, Giacomello R, Stel G, Cecchin E, Sepiacci G, et al. Risk factors for vascular disease and arteriovenous fistula dysfunction in haemodialysis patients. J Am Soc Nephrol. 1996;7(8):1169-77.

38. Mysliwiec M. Vascular access thrombosis-what are the possibilities of intervention? Nephrol Dial Transplant. 1997;12(5):876-8.

39. Cowan DB, Langille BL. Cellular and molecular biology of vascular remodeling. Curr Opin Lipidol. 1996;7:94-100.

40. García-Jérez A, Luengo A, Carracedo J, Ramírez-Chamond R, Rodriguez-Puyol D, Rodriguez-Puyol M, et al. Effect of uraemia on endothelial cell damage is mediated by the integrin linked kinase pathway. J Physiol. 2015;593(3):601-18.
41. Monroy MA, Fang J, Li S, Ferrer L, Birkenbach MP, Lee IJ, et al. Chronic kidney disease alters vascular smooth muscle cell phenotype. Front Biosci (Landmark edition). 2015;20:784-95.

42. Roy-Chaudhury P, Sukhatme VP, Cheung AK. Haemodialysis vascular access dysfunction: a cellular and molecular viewpoint. J Am Soc Nephrol. 2006;17:1112-7.

43. London GM, Pannier B, Agharazii M, Guerin AP, Verbeke FH, Marchais SJ. Forearm reactive hyperemia and mortality in end-stage renal disease. Kidney Int. 2004;65(2):700-4.

44. Verbeke FH, Pannier B, Guérin AP, Boutouyrie P, Laurent S, London GM. Flow-mediated vasodilation in end-stage renal disease. Clin J Am Soc Nephrol. 2011;6(8):2009-15.

45. Owens CD, Wake N, Kim JM, Hentschel D, Conte MS, Schanzer A. Endothelial function predicts positive arterial-venous fistula remodeling in subjects with stage IV and V chronic kidney disease. J Vasc Access. 2010;11(4):329-34

46. Erdem Y, Haznedaroglu IC, Celik I, Yalcin AU, Yasavul U, Turgan C, et al. Coagulation, fibrinolysis and fibrinolysis inhibitors in haemodialysis patients: contribution of arteriovenous fistula. Nephrol Dial Transplant. 1996;11(7):1299-305.

47. Wakefield TW, Myers DD, Henke PK. Mechanisms of venous thrombosis and resolution. Arterioscler Thromb Vasc Biol. 2008:28:387-91.

48. Del Conde I, Lopez J. Classification of venous thromboembolism (VTE) J Thromb Haemost. 2005:3:2573-5.

49. Rekhter M, Nicholls S, Ferguson M, Gordon D. Cell proliferation in human arteriovenous fistulas used for hemodialysis. Arterioscler Thromb. 1993;13:609-17.

50. Kim YO, Choi YJ, Kim Jl, Kim YS, Kim BS, Park CW, et al. The impact of intima-media thickness of radial artery on early failure of radiocephalic arteriovenous fistula in haemodialysis patients. J Korean Med Sci. 2006:21(2):284-9.

51. Sung SA, Ko GJ, Jo SK, Cho WY, Kim HK, Lee SY. Interleukin-10 and tumor necrosis factor-alpha polymorphisms in vascular access failure in patients on hemodialysis: preliminary data in Korea. J Korean Med Sci. 2008;23(1):89-93.

52. Meyerson SL, Skelly CL, Curi MA, Shakur UM, Vosicky JE, Glagov S, et al. The effects of extremely low shear stress on cellular proliferation and neointimal thickening in the failing bypass graft. J Vasc Surg. 2001:34:90-7.

53. Dardik A, Chen L, Frattini J, Asada H, Aziz F, Kudo FA, et al. Differential effects of orbital and laminar shear stress on endothelial cells. J Vasc Surg. 2005;41:869-680.

54. Gambillara V, Montorzi G, Haziza-Pigeon C, Stergiopulos N, Silacci P. Arterial wall response to ex vivo exposure to oscillatory shear stress. J Vasc Res. 2005;42:535-44.

55. Honda HM, Hsiai T, Wortham CM, Chen M, Lin H, Navab $M$, et al. A complex flow pattern of low shear stress and flow reversal promotes monocyte binding to endothelial cells. Atherosclerosis. 2001;158:385-90.

56. Corpataux JM, Haesler E, Silacci P, Ris HB, Hayoz D. Low pressure environment and remodelling of the forearm vein in Brescia-Cimino haemodialysis access. Nephrol Dial Transplant. 2002;17:1057-62.

57. Lehoux S, Castier Y, Tedgui A. Molecular mechanisms of the vascular responses to haemodynamic forces. J Intern Med. 2006;259:381-92.

58. Hayashi K, Mori K, Miyazaki H. Biomechanical response of femoral vein to chronic elevation of blood pressure in rabbits. Am J Physiol Heart Circ Physiol. 2003:284:511-8.

59. Vanholder R, Argilés A, Baurmeister U, Brunet P, Clark W, Cohen G, et al. Uremic toxicity: present state of the art. Int J Artif Organs. 2001;24:695-725.

60. Cardinal H, Raymond MA, Hébert MJ, Madore F. Uraemic plasma decreases the expression of ABCA1, ABCG1 and cell-cycle genes in human coronary arterial endothelial cells. Nephrol Dial Transplant. 2007:22:409-16.

61. Chitalia VC, Murikipudi S, Indolfi L, Rabadi L, Valdez R, Franses JW, et al. Matrix-embedded endothelial cells are protected from the uremic milieu. Nephrol Dial Transplant. 2011;26(12):3858-65.

62. Zadeh MK, Gholipour F, Naderpour Z, Porfakharan M. Relationship between vessel diameter and time to maturation of arteriovenous fistula for haemodialysis access. Int J Nephrol. 2012;3;1-3.

63. Bashar K, Clarke-Moloney M, Burke PE, Kavanagh EG, Walsh SR. The role of venous diameter in predicting arteriovenous fistula maturation: when not to expect an AVF to mature according to pre-operative vein diameter measurements? A best evidence topic. Int J Surg. 2015;15:95-9. 